\title{
ВНЕШНЕЭКОНОМИЧЕСКИЙ ПОТЕНЦИАЛ ЧЕЧЕНСКОЙ РЕСПУБЛИКИ: АНАЛИЗ СОСТОЯНИЯ И ОСНОВНЫЕ НАПРАВЛЕНИЯ ПОВЫШЕНИЯ ЭФФЕКТИВНОСТИ
}

Асхабова 3. P., Минкаилова М. М.

ГГНТУ имени акад. М. Д. Миллионщикова, г. Грозный, Россия

В данной статье рассматривается внешнеэкономическая деятельность как один из важных фактором формирования экономического потенциала региона. Рассмотрена торговая структура экспорта и импорта Чеченской Республики со странами СНГ и Дальнего Зарубежья. Предложены основные направления повышения эффективности использования внешнеэкономического потенциила региона.

Ключевые слова: регион, внешнеэкономический потенциал, внешнеэкономическая деятельность, экспорт, импорт, внешняя торговля.

В современном мировом хозяйстве внешнеэкономические связи являются важным фактором формирования экономического потенциала страны. Эффективное использование регионом внешнеэкономического потенциала способствует внедрению в отечественную экономику элементов здоровой конкуренции, новые технологии, опыт рыночного хозяйствования, обеспечивая прирост национального богатства за счет товарообмена по выгодным ценам и привлечения зарубежного капитала.

В настоящее время Чеченская Республика характеризуется высокой динамичностью процессов возрождения во всех сферах жизни общества и успешным решением социальных, экономических и экологических проблем, возникших в связи с масштабностью общественно-политических проблем, глубиной спадов производства и уровня жизни, повлекших разрушения накопленного экономического потенциала, межрегиональных и международных связей. Положительную роль в расширении рыночного пространства играют соглашения с регионами России, позволяющие решать первоочередные задачи межрегионального сотрудничества [2].

Чеченская Республика обладает комплексом сравнительных конкурентных преимуществ, позволяющих рассчитывать на эффективность внешнеэкономической деятельности. К ним относятся:

- наличие сектора промышленности (в основном оборонного характера), способного к освоению новых видов продукции;

- высокий уровень квалификации целого ряда профессиональных категорий работников при сравнительно низкой заработной плате; 
- большие объемы производственных фондов, позволяющие снизить капиталоемкость технологической модернизации конкретных проектов $\mathrm{c}$ участием иностранного капитала;

- наличие минерального сырьевого потенциала;

- возможности рекреационной, туристической, агропромышленной, промысловой и энергетической специализации, произошедшие изменения в геополитическом положении республики и наличие портового сооружения, транспортных артерий и узлов для транспортировки экспортно-импортных грузов.

Вместе с тем реализация этих преимуществ затруднена рядом факторов, среди которых можно выделить следующие:

- дезинтеграция экономического пространства, потеря традиционных рынков сбыта машинно-технической продукции;

- практическое отсутствие финансово-экономических механизмов формирования и поддержки экспортоориентированных производств и переноса конкурентоспособных технологий военно-технической сферы в гражданское производство;

- слабый экспортный и валютный контроль, что облегчает вывоз капитала и товаров;

- неразвитость финансовой, организационной, технической и информационной инфраструктуры внешнеэкономической деятельности.

Важным направлением работы по развитию международных экономических связей в последние годы становится налаживание сотрудничества со странами ближнего и дальнего зарубежья и участия республики в различных международных экономических форумах [6].

Традиционно значимым для республики является сотрудничество со странами ближневосточного региона, в том числе, участие арабских капиталов в осуществлении инвестиционных проектов на территории Чеченской Республики.

Важное значение для Чеченской Республики имеет сотрудничество со странами СНГ. Укрепление деловых и дружественных отношений с Казахстаном, Азербайджаном, Белоруссии является одним из приоритетных направлений внешнеэкономической деятельности республики. В 2015 году поставки товарной продукции в Чеченскую Республику из Республики Беларусь возросли в 2,3 раза по сравнению с предыдущим годом. В Грозном работает торговый дом «Беларусь», реализующий технику. Кроме этого, республика имеет прямые договора с крупнейшими белорусскими предприятиями: «МАЗ», тракторный завод «Беларусь», завод «Амкадор», завод «Атлант». Из Беларуси поступают в Чеченскую Республику нефтепродукты, строительные материалы, изделия из цемента, бетона, искусственного камня, изделия из черных металлов, трансформаторы, сельскохозяйственные машины и механизмы.

Чеченская Республика регулярно участвует во многих международных экономических форумах и специализированных выставках, в том числе, в 
работе Петербургского Международного экономического форума, Международного экономического форума (Кубань) в г. Сочи, Международного Строительного Форума в г. Дубай (ОАЭ), «BUILDING FUTURES GULF» в г. Канны (Франция) - международная выставка недвижимости «МIPEМ».

Чеченская Республика имеет договорные отношения с 39 субъектами Российской Федерации, зарубежными городами (странами) - Минском (Беларусь), Стамбулом (Турция), провинции Чжэцзян (КНР) и различными бизнес-структурами России и зарубежных стран.

Около 30 участников внешнеэкономической деятельности Чеченской Республики являются юридическими лицами. Внешнеторговый оборот, совершенный участниками ВЭД Чеченской Республики в 2018 году, оценивается в 5,09 млн. долл. США, что выше уровня предыдущего года на $149 \%$ (0,16\% от стоимостных объемов СКФО).

Во внешней торговле доминировали страны дальнего зарубежья с долей товарооборота 76,9\%. Наибольшим по величине был товарооборот с Китаем, Украиной и Словакией.

Основной статьей экспорта республики является машиностроительная продукция (средства наземного транспорта, кроме железнодорожного) с долей $100 \%$ в структуре экспортируемых товаров.

Крупнейшими торговыми партнерами, ввозившими продукцию в республику, были из стран дальнего зарубежья - Китай $(54,63 \%)$, Германия $(8,59 \%)$, Украина $(22,92 \%)$ и Армения $(2,23 \%)$.

Основу импорта в 2018 году составляли товары, относящиеся к категории прочей группы товаров, с долей $50,1 \%$ от стоимостных объемов импорта. Показатели внешнеторговой деятельности Чеченской Республики представлены в таблице 1 [10].

Таблица 1 - Внешнеторговая деятельность Чеченской Республики (млн. долларов США)

\begin{tabular}{|c|c|c|c|}
\hline \multirow{2}{*}{} & \multirow{2}{*}{ Всего } & \multicolumn{2}{|c|}{ В том числе } \\
\cline { 3 - 4 } & & $\begin{array}{c}\text { Страны Дальнего } \\
\text { Зарубежья }\end{array}$ & $\begin{array}{c}\text { Страны } \\
\text { СНГ }\end{array}$ \\
\hline Внешнеторговый оборот & & & 0,8 \\
\hline 2016 & 38,2 & 37,3 & 1,6 \\
\hline 2017 & 46,1 & 44,5 & 3.5 \\
\hline 2018 & 57.3 & 53.8 & 0,7 \\
\hline Экспорт & & & 0,5 \\
\hline 2016 & 1,0 & 0,3 & 0.1 \\
\hline 2017 & 1,9 & 1,4 & 0,1 \\
\hline 2018 & 3.7 & 3.6 & 1,1 \\
\hline 2016 & & & 3.4 \\
\hline 2017 & 37,2 & 37,0 & \\
\hline 2018 & 44,2 & 43,1 & \\
\hline
\end{tabular}


Внешнеторговый оборот Чеченской Республики имеет тенденцию к росту по годам, так в 2016 году внешнеторговый оборот составил 38,2 млн. долларов в США, в том числе со странами дальнего зарубежья 37,3 млн. долларов, со странами Содружества независимых государств 0,8 млн. долларов. В 2017 году внешнеторговый оборот вырос до 46,1 млн. долларов, но есть на 7,9 млн. долларов, в том числе со странами дальнего зарубежья 44, 5 млн. долларов и со странами Содружества независимых государств 1,6 млн. долларов, внешнеторговый оборот в 2018 году вырос до 57,3 млн. долларов США, то есть на 9,2 млн. долларов, по сравнению с предыдущим годом, в том числе, оборот торговли со странами дальнего зарубежья составил 53,8 млн. долларов, со странами Содружества Независимых Государств 3,5 млн. долларов, с которыми вырос в два раза. Существенную долю во внешнеторговом обороте составляет импорт, так в 2016 году импорт составил 37,2 млн. долларов, в том числе 37,0 долларов составил импорт со странами дальнего зарубежья и 0,1 млн. долларов со странами Содружества Независимых Государств, в 2017 году импорт вырос до 44,2 млн. долларов, а в 2018 году импорт составил 53,6 млн. долларов в том числе со странами дальнего зарубежья 50,2 млн. рублей и 3,4 млн. долларов со странами Содружества Независимых Государств. Н экспорт в 2016 году приходится 1,0 млн. долларов, в 2017 году 1,8 млн. долларов, а в 2018 году в два раза, по сравнению с предыдущими годами.

Анализ таблицы показывает, что внешнеторговая деятельность Чеченской Республики по годам имеет тенденцию к росту со странами дальнего зарубежья и Содружества Независимых Государств, эта тенденция сохраняется по экспорту и импорту.

Товарная структура экспорта и импорту представлена в таблице 2 [10].

Таблица 2. - Торговая структура экспорта и импорта Чеченской Республики

\begin{tabular}{|l|c|c|c|c|c|c|}
\hline & \multicolumn{2}{|c|}{ Экспорт } & \multicolumn{2}{c|}{ Импорт } \\
\cline { 2 - 7 } & $\begin{array}{c}\text { Страны } \\
\text { Дальнего } \\
\text { Зарубежья }\end{array}$ & $\begin{array}{c}\text { Страны } \\
\text { СНГ }\end{array}$ & Всего & $\begin{array}{c}\text { Страны } \\
\text { Дальнего } \\
\text { Зарубежья }\end{array}$ & $\begin{array}{c}\text { Страны } \\
\text { СНГ }\end{array}$ & Всего \\
\hline $\begin{array}{l}\text { Продовольственные } \\
\text { товары и } \\
\begin{array}{l}\text { сельскохозяйственное } \\
\text { сырье }\end{array}\end{array}$ & 2954,1 & 66,5 & 3020,6 & 168,0 & 160,7 & 328,7 \\
\hline Минеральные продукты & - & - & - & - & 6,5 & 6,5 \\
\hline $\begin{array}{l}\text { Продукция химической } \\
\text { промышленности, каучук }\end{array}$ & - & - & - & 1047,7 & 1,0 & 1048,7 \\
\hline $\begin{array}{l}\text { Кожевенное сырье, } \\
\text { пушнина и изделия из } \\
\text { них }\end{array}$ & - & - & - & 0,9 & - & 0,9 \\
\hline $\begin{array}{l}\text { Древесина и целлюлозно } \\
\text {-бумажные изделия }\end{array}$ & 270,9 & 26,7 & 297,7 & 375,5 & - & 375,5 \\
\hline $\begin{array}{l}\text { Текстиль, текстильные } \\
\text { изделия и обувь }\end{array}$ & - & - & - & 1898,7 & - & 1898,7 \\
\hline $\begin{array}{l}\text { Металлы и изделия из } \\
\text { них }\end{array}$ & - & - & - & 2872,7 & 1033,0 & 3905,7 \\
\hline
\end{tabular}




\begin{tabular}{|l|c|c|c|c|c|c|}
\hline $\begin{array}{l}\text { Машины, оборудование и } \\
\text { транспортные средства }\end{array}$ & 9,5 & - & 9,5 & 31943,1 & - & 31943,7 \\
\hline Другие товары & - & - & - & 2888,0 & 42,4 & 2930,4 \\
\hline
\end{tabular}

Экспорт продовольственных товаров и сельскохозяйственного сырья составлял 3020,6 тысяч долларов США, в том числе в страны дальнего зарубежья 2954,1 тысяч долларов и в страны Содружества Независимых Государств составлял 66,5 тысяч и долларов. Импорт продовольственных товаров и сельскохозяйственного сырья составил 328,7 тысяч долларов, в том числе из стран дальнего зарубежья 168,0 тысяч долларов и из стран Содружества Независимых Государств - 160,7 тысяч долларов. Продукция химической промышленности в основном ввозится из стран дальнего зарубежья, а экспорта нет. Экспорт древесины и целлюлозно-бумажных изделий составил 297,7 тысяч долларов, из которых 270,9 тысяч долларов приходится на экспорт со странами дальнего зарубежья и 26,7 тысяч долларов в страны Содружества Независимых Государств. Импорт древесины и целлюлозно-бумажной продукции составляет 375,5 тысяч долларов, и только из стран дальнего зарубежья. Экспорта текстильных изделий и обуви из России нет, а импорт этой продукции составляет 1898,7 тысяч долларов и только из стран дальнего зарубежья.

Экспорта металла и металлических изделий в настоящее время нет, импорт этих товаров составляет 2930,4 тысяч долларов, в том числе из стран дальнего зарубежья 2888,0 тысяч долларов и 42,4 тысяч долларов из стран Содружества Независимых Государств.

Экспорт машин и оборудования составляет 9,5 тысяч долларов, и в основном, в страны дальнего зарубежья, а импорт этих товаров составляет 3905,7 тысяч долларов, в том числе из стран дальнего зарубежья 2872,7 тысяч долларов и стран Содружества Независимых Государств - 1033,0 тысяч долларов. Оборот внешней торговли представлен в таблице 3 [10].

Таблица 3 - Оборот внешней торговли Чеченской Республики

\begin{tabular}{|l|c|c|l|}
\hline & Страны Дальнего Зарубежья & Со странамит СНГ & Всего \\
\hline Экспорт & 3,2 & 0,1 & 3,3 \\
\hline Импорт & 41,2 & 1,2 & 42,4 \\
\hline Сальдо & $-38,0$ & $-1,1$ & $-39,1$ \\
\hline
\end{tabular}

Источник: даннье таможенной статистики

Как видно по данным таблицы, основная доля экспорта 3,2 млн. долларов приходится на страны дальнего зарубежья из общего объема 3,3 млн. долларов, импорта на страны дальнего зарубежья приходится 41,2 млн. долларов. Оборот внешней торговли с отрицательным сальдо, то есть - 38,0 млн. долларов со странами дальнего зарубежья и - 1,1 млн. долларов со странами Содружества Независимых Государств, а общий оборот - 39,1 млн. долларов.

Создание и функционирование глобальной системы продвижения республиканской продукции на внешних рынках требует реализации комплекса 
экономических, финансовых и организационных мер, наиболее важными из которых являются:

- разработка приоритетов внешней экономической политики Чеченской Республики для стран, регионов, сырьевых рынков, групп потребителей с учетом интересов Республики и их последовательного осуществления, включая скоординированные действия зарубежных торговых представительств;

- создание эффективной системы поддержки полупрозрачных продуктов на внешнем рынке, защита интересов участников внешнеэкономической деятельности Республики;

- создание информационной системы цен (внутренней и внешней) ;

- участие в экономических обменах с субъектами Российской Федерации неиспользованных экспортных ресурсов регионов и укрепление экспортного потенциала республики на этой основе;

- совершенствование законодательства с целью повышения эффективности внешнеэкономических связей между хозяйственными субъектами, расположенными на приграничных территориях.

В настоящее время следует выделить такие пути совершенствования экспортного потенциала Чеченской Республики, как:

- ускорение конверсии и перепрофилирования действующих оборонных заводов на выпуск высококачественной продукции гражданского назначения;

- стимулирование развития мощностей по переработке шерсти, кожи, производств по выпуску разнообразных товаров народного потребления;

- совершенствования экспортной специализации сельского хозяйства республики.

Сельское хозяйство остается одной из важнейших областей экономики Чеченской Республики. В настоящее время на него приходится почти треть валового государственного продукта. С этой точки зрения и с учетом в целом благоприятных климатических условий Северного Кавказа, с учетом традиций сельского хозяйства и животноводства, характерных для народа Чеченской Республики, расширение и совершенствование экспорта сельскохозяйственной продукции предполагает:

- выращивать сортов семенного зерна;

- разводить элитные породы скота, а также расширить забой обычного скота по мусульманским обычаям с последующим расширением его экспорта в исламские страны Ближнего и Среднего Востока;

- культивировать и переработать экологически чистые сельскохозяйственных продукты;

- сбор дикорастущих и разведение для последующего экспорта лекарственных растений;

- развитие пчеловодства для увеличения экспорта меда, пчелиного яда, прополиса, пчелиного молочка;

- развитие виноградарства, улучшение сортности винограда, расширение сети предприятий, производящих коньячную и винодельческую продукцию; 
- организацию в каждом районе республики производств по переработке сельскохозяйственного сырья.

По нашим подсчетам, увеличение объемов экспорта только указанных выше видов продукции на 30-40 процентов обеспечило бы дополнительный приток в республику валютных средств на сумму 60-80 миллионов долларов.

Необходимо всяческое стимулирование развития производства таких товаров традиционного экспорта, как продукция народных художественных промыслов. В мире хорошо известны уникальные изделия из золота, серебра, мельхиора, дерева, гончарные изделия.

Республике следует предпринимать активные меры к достижению этих целей, например, разработать различные проекты в сфере внешнеэкономической деятельности, к которым можно отнести проекты о создании свободной экономической зоны на территории республики, реализация которого даст большие доходы для республиканского бюджета. Целесообразно также образование на территории Чеченской Республики свободной таможенной зоны. Все это позволит существенно повысить доходность экспортной ориентации производства на территории республики.

\section{Исследование выполнено при финансовой поддержке РФФИ в рамках научного проекта №18-010-00182.}

\section{Список литературы}

1. Асхабова 3.Р. Зарубежный опыт повышения эффективности внешнеторговой деятельности предприятий // МОЛОДЕЖЬ, НАУКА, ИННОВАЦИИ. Материалы VII Всероссийской научно-практической конференции. Грозный: ГГНТУ, 2018. С.12-17.

2. Асхабова 3.Р., Асхабов Р.Ю., Бетилгириев М.А Влияние внешнеторговой деятельности на развитие предприятий промышленности Чеченской Республики // Современные проблемы экономики, бизнеса и инновационного развития. Материалы Всероссийской научно-практической конференции. г. Грозный, 2018г. С. 86 - 93.

3. Имяреков С.М. Внешняя и внутренняя политика России в начале XXI века [Электронный ресурс]: учебное пособие для вузов / С.М. Имяреков, О.Б. Кевбрина, В.С. Имяреков. - Электрон. текстовые данные. - М.: Академический Проект, 2017. - 238 с. — 978-5-8291-2553-0. — Режим доступа: http://www.iprbookshop.ru/68321.html

4. Крайнова О.С. Методология оценки конкурентоспособности потребительских товаров [Электронный ресурс]: учебное пособие / О.С. Крайнова. - Электрон. текстовые данные. - Саратов: Вузовское образование, 2018. - 130 с. - 978-5-4487-0268-6 - Режим доступа: http://www.iprbookshop.ru/76926.html

5. Куприянов С.В. Организация и техника внешнеэкономических операций [Электронный ресурс]: учебное пособие / С.В. Куприянов, К.С. 
Борзенкова. - 2-е изд. - Электрон. текстовые данные. - Белгород: Белгородский государственный технологический университет им. В.Г. Шухова, ЭБС АCB, 2017. - 179 с. - 2227-8397. - Режим доступа: http://www.iprbookshop.ru/80431.html

6. Минкаилова М.М., Асхабова 3.Р., Идилова Р.Х. Роль функционирования систем электронной торговли для развития межрегиональных (продовольственных) связей // Актуальные вопросы современной науки. Вестник науки. Сборник статей по материалам IX Международной научно-практической конференции. Часть 1(2), Томск, 2018. C. $213-221$.

7. Минько Э.В. Организация коммерческой деятельности промышленного предприятия [Электронный ресурс] : учебное пособие / Э.В. Минько, А.Э. Минько. - Электрон. текстовые данные. - Саратов: Ай Пи Эр Медиа, 2017. - 404 с. - 978-5-4486-0021-0. - Режим доступа: http://www.iprbookshop.ru/74228.html.

8. Опасные и вредные факторы производственной среды [Электронный pecypc]: учебное пособие / Д.О. Литвинов [и др.]. - Электрон. текстовые данные. - Саратов: Вузовское образование, 2018. - 90 с. - 978-5-4487-02242. - Режим доступа: http://www.iprbookshop.ru/74965.html

9. Уткина С.И. Внешнеэкономическая деятельность [Электронный pecypc]: учебное пособие / С.И. Уткина, Э.А. Попова. - Электрон. текстовые данные. - М.: Издательский Дом МИСиС, 2017. — 132 с. — 978-5-906846-617. - Режим доступа: http://www.iprbookshop.ru/71668.html

10. Официальный сайт Территориального органа Федеральной службы государственной статистики по Чеченской Республике: http://chechenstat.gks.ru/

11. Официальный сайт Министерства экономического развития РФ: http://economy.gov.ru/minec/about/structure/.

12. Официальный сайт Министерства экономического, территориального развития и торговли Чеченской Республики: http://chechnya.gov.ru/. 